\title{
JUSTICIA Y SEGURIDAD EN LAS NOTICIAS SOBRE EL CRIMEN: LA CONSTRUCCIÓN TELEVISIVA DE UN PROBLEMA SOCIAL*
}

\author{
Ricardo Gutiérrez **
}

Fecha de recepción: febrero 2000

Fecha de aceptación y versión final: abril 2000

Resumen: Con un análisis de los telenoticieros argentinos el autor nos desvela las definiciones mediáticas del crimen, así como el papel atribuido a las instituciones políticas y a los propios medios en las noticias sobre ese "problema social". A partir de esta información, se apuntan algunas dificultades de la ciudadanía para entender y participar en una solución política de los problemas del orden y la justicia sociales.

Palabras Clave: Medios de comunicación, televisión, informativos, análisis de discurso, problemas sociales, crimen, instituciones políticas, Argentina.

Abstract: Analyzin argentine tv news, the author describes the media definitions of crime, and the role of political institutions and the same media in the news about this "social problem". From this information are established some difficults of the citizens to understand and participate in the polítical solution of the order and social justice problem.

Key Words: Mass media, tv news, discourse analysis, social problems, crime, political institutions, Argentine.

\section{INTRODUCCIÓN}

\section{El tema}

La justicia y la seguridad se han convertido, durante los años 90, en temas prioritarios de la agenda pública argentina, llegando a constituirse, desde 1997, en temas principales -tal vez los más "urgentes"- de la agenda política. Con anterioridad a 1990, los resultados de las encuestas de opinión pública no solían incluir a la justicia y a la seguridad como aquellos temas que la población consideraba más preocupantes y cuya resolución se exigía perentoriamente de parte del gobierno. Los problemas sociales prioritarios para la opinión pública eran, durante los años de Raúl Alfonsín, la inflación, el salario y el empleo.

Los protagonistas claves de la instalación pública de la justicia y la seguridad como temas prioritarios han sido, sin duda, los medios de comunicación. Los medios han "construido" 1 la falta de justicia y de seguridad como un problema social y se han convertido en "voceros" de nuevas formas de reclamos cuyo epítome lo han constituido las "Marchas del Silencio". Fue dicha construcción -junto con la presunción de que la misma está en sintonía con la opinión mayoritaria de la población- lo que llevó a la clase política a incorporar a la justicia y la seguridad entre los temas prioritarios de su agenda.
Entre los medios y géneros de comunicación masiva, los telenoticieros han jugado un papel privilegiado en esa historia. Existen, para ello, tres razones: (1) el alto nivel de recepción de los telenoticieros 2 , (2) el alto grado de tratamiento que los telenoticieros otorgan a la justicia y a la seguridad en su producción de noticias y (3) el carácter objetivo con el cual los telenoticieros pretenden llevar a cabo su tarea.

Los telenoticieros han privilegiado -no casualmenteun ámbito específico para la construcción de la justicia y la seguridad como bienes públicos: el relato sobre el mundo

* Este trabajo se basa en los resultados finales de una investigación realizada entre 1993 y 1996 con el financiamiento de la Universidad de Buenos Aires.

* Instituto de Investigaciones Gino Germani, Universidad de Buenos Aires. $\bowtie$ ariccia@hotmail.com

1. Hablo de construcción tanto en el sentido otorgado a ese término por la sociosemiótica (ver Verón 1967, 1983a, 1983b, 1986, 1987b y Rodrigo Alsina 1989) como en el sentido otorgado por el enfoque constructivista de los problemas sociales (ver Best 1989, Frigerio 1995, Goode \& Ben-Yehuda 1994, Hilgartner \& Bosk 1988, Schneider 1985 y 1993).

2. Según las mediciones de las consultoras especializadas, el telenoticiero ha sido uno de los tipos de programas de televisión abierta más vistos durante la última década. En el caso de los canales porteños 9, 11 y 13 (los principales canales del país), los noticieros han alcanzado un valor de rating que, en promedio, iguala o supera los 10 puntos, esto es, el millón de personas. El avance de la televisión por cable, por su parte, no ha hecho más que expandir ese predominio de los telenoticieros. 
del crimen. Es allí donde reafirman el valor de la justicia y la seguridad como bienes públicos primarios de la sociedad. Es allí también donde representan y refuerzan, a su modo, los reclamos de justicia y seguridad. En este trabajo, se analiza un corpus de noticias correspondientes a tres telenoticieros porteños con el objetivo de examinar (1) el modo en que el relato de los telenoticieros define a la justicia y la seguridad como bienes públicos primarios a partir de la construcción de la criminalidad como un problema social y (2) el papel que dicho relato otorga a las instituciones políticas y a los propios telenoticieros en referencia al mundo del crimen.

Justicia, seguridad y criminalidad constituyen, en el relato de los telenoticieros, una misma tríada semántica. Mientras la justicia y la seguridad son presentadas como bienes complementarios, la ausencia de ambas se manifiesta en un mismo problema social: la criminalidad. La falta de justicia y de seguridad equivalen a la criminalidad. Como si dijésemos: "si no hay justicia, si no hay seguridad, lo que hay es, simplemente, criminalidad". La criminalidad sintetiza, como problema social, la no satisfacción de la justicia y de la seguridad como bienes públicos. Es por eso que los telenoticieros tematizan dichos bienes en su relato sobre el mundo del crimen.

Las noticias sobre el crimen "ofrecen" a los telenoticieros una ventaja comparativa respecto de otro tipo de noticias, especialmente, respecto de las noticias políticas o económicas: la ventaja de poder valorar y censurar un hecho "objetivamente", esto es, sin que ello pueda ser considerado como una toma de posición parcial o facciosa. Esto es asî porque el crimen representa, en el discurso de los telenoticieros $^{3}$, el máximo peligro que amenaza, como exterioridad radical, a la sociedad. El criminal es, en efecto, el otro radical de la sociedad, aquel cuya existencia amenaza, por definición, la existencia de la sociedad. Por lo tanto, censurar un caso criminal, valorarlo negativamente y reclamar que sea condenado no es más que bregar por la sobrevivencia de la sociedad. De ahí el carácter objetivo de la censura. Se trata de una objetividad fundamentada de modo convencional mediante un consenso unánime entre el enunciador televisivo y la audiencia televidente: "nadie quiere, nadie puede querer -parece decir el telenoticiero- que la sociedad estalle en mil pedazos, nadie duda que el crimen es malvado, lo absolutamente malvado". Por eso, sostener que el crimen debe ser censurado y "combatido" y que el criminal debe ser castigado no es un mero juicio moral o valorativo; es una verdad sobre la cual nadie puede dudar o, en todo caso, un valor que nadie puede no afirmar.

Cuando desde el relato sobre los casos criminales se avanza hasta el reclamo de justicia y seguridad dirigido hacia el sistema político, la fertilidad de la recurrencia al mundo del crimen parece insuperable: podemos dirigirnos al mundo político, podemos interpelar a la clase política y exigirle que tome medidas sin que esa actividad resulte facciosa, partidaria o interesada. Podemos plantear exigencias políticas apolíticamente, apoyados en la objetividad que nos otorga el rechazo universal del crimen. En este punto es notoria la afinidad entre la tematización que los noticieros hacen de la justicia y la seguridad y el modo en que las
Marchas del Silencio, como nuevo tipo de protesta, expresan su reclamo: sin banderas, sin política, con una legitimidad pretendidamente indiscutible.

Las Marchas del Silencio fueron incorporadas al repertorio argentino de protestas a partir de un resonante caso criminal conocido como el "caso María Soledad". Desde entonces, fueron utilizadas como forma privilegiada para la expresión de distintos reclamos de justicia y/o seguridad.

En septiembre de 1990, pobladores de la ciudad de Catamarca, en el norte argentino, protagonizaron la primera de una larga serie de movilizaciones callejeras con el propósito de reclamar el esclarecimiento judicial del asesinato de la joven María Soledad Morales, una estudiante secundaria de un colegio católico. Esas movilizaciones fueron identificadas por sus protagonistas y por el periodismo como "Marchas del Silencio". Esa denominación respondía tanto a la modalidad de expresión utilizada durante las movilizaciones como a la búsqueda intencional -de parte de los organizadores- de evitar la partidización manifiesta de las mismas, aún cuando los principales sospechosos del crimen estaban estrechamente vinculados con el partido gobernante.

A pesar de que el asesinato de María Soledad Morales fue el detonante de una protesta generalizada contra el nepotista sistema político catamarqueño (protesta que desembocó en el desplazamiento del tradicional partido gobernante de la provincia -el peronismo-), todas las Marchas del Silencio vinculadas con el caso reunían dos características constantes: el esclarecimiento judicial como reclamo exclusivo y la ausencia de banderas políticas o de cualquier otro tipo. No se trataba solamente de marchar silenciosamente, sino también de silenciar toda apropiación política. No parece desacertado afirmar que el extraordinario atractivo que tendrían las Marchas del Silencio como forma de protesta provendría de esas dos características, las cuales, para decirlo de otro modo, combinaban el reclamo de un bien considerado primario -justicia, seguridad-con la naturaleza "pura" y "no contaminada" -no política- de sus motivaciones. He ahí, también, la clave de la amplia cobertura que los telenoticieros han otorgado a las Marchas del Silencio y, de modo más general, del papel que se han otorgado a sí mismos como "representantes" de la población, en materia de justicia y seguridad, ante las instituciones políticas.

\section{El corpus}

El corpus de análisis se compone de todas las noticias emitidas por tres noticieros porteños de televisión abierta entre junio y noviembre de 1994. Los telenoticieros seleccionados eran, a la fecha de registro del corpus, los de mayor

3. Y no sólo en ese discurso. Basta con considerar la teoría política para encontrar un tipo de discurso que, casi constitutivamente, hace del rechazo del crimen y de su exteriorización radical el recurso para la delimitación del orden social. 
audiencia en el área metropolitana de Buenos Aires y sus alrededores; a saber: TELEFE NOTICIAS Segunda Edición, TELENOCHE y NUEVEDIARIO Segunda Edición.

El análisis del corpus fue realizado en base a un modelo de componentes semánticos mínimos para cuya definición se ha recurrido al modelo actancial de Greimas (1987) 4, el cual permite analizar la estructura de un relato en base a un número limitado de figuras narrativas. En nuestro caso, se han utilizado las siguientes figuras:

Función: conjunto o tipo de acciones que un sujeto realiza, se propone realizar o se considera que debe realizar.

Sujeto: actante que se destina a sí mismo o es destinado por otros a realizar la función.

Objeto: actante que recibe o padece la función.

Adyuvante: actante que colabora con el sujeto en la realización de la función.

Oponente: actante que impide o se opone a que se realice la función.

Destinador: actante que otorga al sujeto su poder de realizar la función y en nombre de quien éste la realiza.

Destinatario: actante para quien es realizada la función o para quien están destinados los resultados de la misma.

Para el análisis específico de las noticias sobre el crimen, se ha definido, además, la siguiente estructura narrativa o "fórmula de la criminalidad":

\begin{tabular}{|c|c|c|c|}
\hline \multirow[b]{3}{*}{$\begin{array}{r}\text { victimario } \\
\quad \text { (sujeto) }\end{array}$} & \multicolumn{3}{|c|}{ oponente } \\
\hline & \multicolumn{3}{|c|}{$\downarrow$} \\
\hline & $\rightarrow$ & $\begin{array}{l}\text { CRIMEN } \rightarrow \\
\text { (función) }\end{array}$ & $\begin{array}{l}\text { victima } \\
\text { (objeto) }\end{array}$ \\
\hline & & $\uparrow$ & \\
\hline & & dyuvante & \\
\hline
\end{tabular}

donde alguien (el victimario) comete un CRIMEN en detrimento de alguien (la víctima) con el posible concurso de alguien (el adyuvante) y la posible oposición de alguien (el oponente).

Respecto del corpus, cabe advertir que, si bien data de cinco años atrás, los resultados obtenidos no han perdido actualidad dado que el estilo narrativo de los telenoticieros no ha variado desde entonces y que la justicia y -sobre todo- la seguridad siguen ocupando la primera plana de los temas que más preocupan a los mismos.

En la Sección I, se analiza, con base en el corpus señalado, la construcción que los telenoticieros hacen de la criminalidad como un problema social vis a vis los otros temas sociales. En la Sección II, se reconstruye el papel ambiguo que los telenoticieros otorgan a las instituciones políticas 5 en su relato sobre el mundo del crimen. En la última sección, se aborda el papel que los telenoticieros se otorgan a sí mismos, en referencia al problema de la criminalidad y en contraposición a las instituciones políticas, como defensores de la justicia y la seguridad.

\section{LA CONSTRUCCIÓN DE LA CRIMINALIDAD COMO UN PROBLEMA SOCIAL}

Mediante las noticias, los telenoticieros no sólo nos brindan una imagen del mundo sino que nos ofrecen también categorías para aprehenderlo y sistematizarlo; nos dicen cuáles son los temas más relevantes o más interesantes, cómo se relacionan dichos temas entre sí y cuáles de ellos deben ser considerados como problemas sociales. Sin lugar a dudas, los telenoticieros no constituyen la única fuente a partir de la cual construimos nuestra imagen del mundo, no es siquiera la única fuente mediática. En el caso de la televisión -de aire o por cable-, cualquier tipo de programa puede ser un referente a partir del cual construimos nuestra imagen de lo que es el mundo o de lo que debe ser. Sin embargo, el género informativo tiene respecto de otros géneros o transgéneros una capacidad diferencial: la de pretender la objetividad referencial de su discurso ${ }^{6}$.

Se ha escrito y discutido mucho sobre el poder y los efectos de los medios. Apocalípticos e integrados han logrado reunir igual cantidad de argumentos y evidencias. Aunque la polémica sigue sin saldar, es insoslayable que los medios ejercen una muy fuerte influencia en la definición de la agenda pública de los temas prioritarios 7 . Como afirma B. Cohen, "la prensa no puede durante mucho tiempo tener éxito diciéndole a la gente qué tiene que pensar, pero sí diciéndole sobre qué tiene que pensar" (citado en Dader, 1990:295) 8. La agenda-setting research ha demostrado largamente la solidez de ese axioma 9 . Pero cabe decir aún más. Extendiendo la frase de Cohen, puede afirmarse que, diciéndole sobre qué pensar, los medios informativos le dicen a la gente cuáles son los grandes problemas sociales. Como señala A. Agostini, los problemas sociales de todo tipo (políticos, económicos, culturales, de costumbres, morales) constituyen uno de los principales objetos de la tematización mediática 10 . Por eso, si queremos investigar los procesos mediante los cuales son definidos los problemas sociales públicamente, no debemos descuidar el estudio de la tematización del mundo 11.

4. Ver también Greimas (1993), Eco (1981) e Imbert (1990).

5. En este trabajo, probablemente utilice el término instituciones políticas en un sentido laxo respecto de sus acepciones más comunes. Me interesa resaltar que se trata de aquellas instituciones de las cuales se espera que actúen como garantes estatales y políticos del orden social.

6. Existe una extensa bibliografía sobre este último punto; ver, por ejemplo, Verón (1983a, 1987a, 1987b), Rodrigo Alsina (1989).

7. Ver Dader (1990), Edelman (1991), Frigerio (1995) y Rodrigo Alsina (1989).

8. Ver también Frigerio (1995) y Rodrigo Alsina (1989).

9. Ver Dader (1990), De Fleur \& Ball-Rokeach (1991) y Rodrigo Alsina (1989).

10. Ver Rodrigo Alsina (1989)

11. En este punto, tomo distancia respecto de los enfoques constructivistas de los problemas sociales que se centran en la actividad de los claims-makers o "reclamadores". Como afirman Hilgartner \& Bosk, muchos actores que participan del proceso de definición de problemas sociales no deben ser vistos como "activistas": "el principal objetivo de algunos actores que formulan problemas sociales - productores de televisión, abogados, especialistas en relaciones públicas- puede ser hacer dinero más que provocar o resistir el cambio social. Para algunos, los problemas sociales constituyen simplemente otro día de oficina" (1988:57; traducción mía). 
¿Qué miramos, entonces, cuando miramos los noticieros? 12. Supongamos, para comenzar, un televidente modelo que decide mirar determinado noticiero y lo hace durante el tiempo total del mismo, tiempo que estimaremos en sesenta minutos. Nuestro televidente observará entre un 19 y un $24 \%$ de avisos publicitarios -según qué noticiero haya elegido-, entre un 2 y un $4 \%$ de tiempos netamente institucionales 13 y, finalmente, entre un 73 y un $78 \%$ de noticias, lo cual equivale a un tiempo real de cuarenta y cinco minutos. ¿Qué mirará, entonces, nuestro televidente durante esos cuarenta y cinco minutos? 14 .

Para comenzar, consideremos el conjunto de las noticias y clasifiquémoslas según los siguientes temas: Criminalidad, Política Interna, Relaciones Internacionales, Salud, Servicios Públicos, Accidentes y Catástrofes, Medio Ambiente, Juegos de Azar y Apuesta, Religión, Condiciones Meteorológicas, Deportes, Espectáculos, Moda y Programación del Canal ${ }^{15}$. De esta clasificación resulta que los temas de mayor cobertura son Criminalidad, Política Interna y Deportes. Los guarismos son los siguientes: en el caso de TELEFE, Criminalidad $28 \%$, Política Interna 20 $\%$ y Deportes $15 \%$; en el caso de TELENOCHE, Criminalidad $25 \%$, Política Interna $24 \%$ y Deportes 17 $\%$; en el caso de NUEVEDIARIO, Criminalidad $25 \%$, Deportes $17 \%$ y Política Interna $16 \%$-ver Cuadros $1 . A$, 1.B y 1 .C-.

CUADRO I.A
DISTRIBUCION TEMATICA DEL TOTAL DE LA NOTICIAS

TELEFE - en porcentajes

\begin{tabular}{|c|c|c|c|}
\hline (RIMINALLIDAI) & $27.53^{\circ} \circ$ & REELIGION & $0.72^{\circ} \circ$ \\
\hline IOIITICA INTTRNA & $19.81^{\circ} \circ$ & JUIGOS DE NARAPUISTA & (1).68\% \\
\hline DAPORTIS & $14.47^{\circ} \circ$ & (ONI) METTOROLOGICAS & $0.61^{\circ} \circ$ \\
\hline SI:RVICIOS PUIIIIICOS & $4.74^{\circ} \circ$ & MOIIA & $0,38^{\circ} \circ$ \\
\hline ACCII) y CATASTROHIS & $4.11^{\circ} \mathrm{o}$ & IROACRAMACION & $1024^{\circ} \circ$ \\
\hline REII. INTT:RNACIONAIIIS & $4.06^{\circ} \circ$ & OTROS TEMAS & $5.63^{\circ} \circ$ \\
\hline SAIUI) & $3.99^{\circ} \mathrm{o}$ & SIN ISPPICIFICAR & $6.45^{\circ} \circ$ \\
\hline ВВРЕСТАСUIOA & $3.58^{\circ} \circ$ & & \\
\hline MI:DXO $\triangle M B B I I N$ NTT: & $3.01 \%$ & TOTAI. & $\mid(x):(x)^{0}$ \\
\hline
\end{tabular}

CUADRO I.B

DISTRIBUCION TEMATICA DEL TOTAL DE LAS NOTICIAS

TELENOCHE - en poree ntajes

\begin{tabular}{|c|c|c|c|}
\hline CRIMINALLIIDAI) & $24.53^{\circ} \circ$ & CONI) METTEOROLOCIICAS & $1.45^{\circ}$ \\
\hline FOITICA INTERNA & $23.9 \% \mathrm{O}^{\circ}$ & RILLIGION & $0.86^{\circ}$ 。 \\
\hline DXIYORTIS & $17.50^{\circ} \circ$ & JUEGGO DI: AZAR/APUESTA & $0.74^{\circ}$ \\
\hline ISPECTACULOS & $6.50^{\circ} \mathrm{\circ}$ & MOIN & $0.66^{\circ} \circ$ \\
\hline REI__ INTTRNACIONALIES & $490^{\circ}$ 。 & OTROS TEMAS & $5 . x^{\circ}$ \\
\hline ACCIII. Y CATASTROHS & $2.68^{\circ} \circ$ & SIN ISPCIFICAR & $3.72^{\circ}$ \\
\hline SALUD & $2.67^{\circ} \circ$ & & \\
\hline SI:RVICIOS PUIHLICOK & $202^{\circ} \mathrm{o}$ & & \\
\hline MI:IXO $\triangle$ MBIIIINTE: & $1.99 \%$ & TOTAL & I(1).0.010 \\
\hline
\end{tabular}

CUADRO I.C
DISTRIBUCION TEMATICA DEL TOTAL DE LAS NOTICIAS NUEVEDIARIO - en porcentajes

\begin{tabular}{|c|c|c|c|}
\hline (RIMINALIII)AD) & $24.87^{\circ}$ 。 & REIIIGION & $1.46^{\circ} \mathrm{o}$ \\
\hline DECPORTES & $17.08^{\circ} \circ$ & COND. METEOROLOGICAS & $0.70^{\circ}$ \\
\hline POHTICA INTIERNA & $15.96^{\circ} \circ$ & PROGGRAMACION & $0.6)^{\circ} \circ$ \\
\hline SALUD & $10.18^{\circ} \circ$ & ME:IXO $\triangle M B I I E N T E$ & $0.53^{\circ}$ 。 \\
\hline ACCIIDY CATASTROFIS & $7.57^{\circ} \circ$ & MOIX & $0.22{ }^{\circ} \circ$ \\
\hline REI. INIIERNACIONALLES & $3.78^{\circ} \circ$ & OTROS TEMAS & $5.03^{\circ} \circ$ \\
\hline ISP:CTACULOK & $3.56^{\circ} \circ$ & SIN ESPIECIFICAR & $4.85^{\circ} \circ$ \\
\hline ЛH:GOS DE:АZАRAPU:STA & $2.06^{\circ}$ & & \\
\hline SIRVVICIOS PUIILIKCK & $1.57^{\circ}$ & TOTAL. & $1000.000^{\circ}$. \\
\hline
\end{tabular}

Tenemos, entonces, un primer cuadro en el cual la criminalidad, la política interna -temas políticos y económicos-y el deporte concentran, en promedio, más del $60 \%$ de las noticias, mientras que las noticias restantes se reparten entre una miríada de temas divergentes. Consideremos ahora esa tríada temática para realizar algunos comentarios respecto de sus modalidades narrativas.

Una primera observación nos permite afirmar que existen dos importantes diferencias entre las noticias sobre criminalidad y las noticias políticas y económicas.

La primera diferencia se refiere a la estructura narrativa de las mismas. En el caso de las noticias sobre criminalidad, aún cuando se refieren a una constelación de acontecimientos diversos -incluidos algunos de violencia política-, es posible identificar una estructura mínima común al relato de los distintos acontecimientos-base 16 , la cual puede expresarse bajo la fórmula actancial

$$
\text { Victimario } \rightarrow \text { Delito } \rightarrow \text { Víctima }{ }^{17} \text {. }
$$

En el caso de las noticias políticas, en cambio, es difícil identificar una estructura narrativa común a los diversos acontecimientos relatados, dado que no es factible encon-

12. Vale una aclaración. Averiguar qué vemos en los noticieros no equivale a determinar el modo en que sus audiencias se apropian de las noticias. Recordemos el clásico axioma de la sociosemiótica: entre la producción y la recepción existe una relación de asimetría tal que de la descripción de las operaciones de la primera no puede derivarse un modo unívoco de recepción. En nuestros términos: nada nos habilita a pensar que la imagen del mundo ofrecida por los telenoticieros será asumida como propia por sus audiencias. Con todo, conviene no desestimar las advertencias de la agenda-setting research sobre la capacidad canalizadora de los medios. De hecho, el principio de canalización sintoniza bastante bien con el de asimetría en tanto ambos señalan que, en el caso de la producción mediática, la misma tiene suficiente capacidad como para influir sobre sus audiencias, pero no tanto como para modelar unilateralmente sus representaciones sobre el mundo.

13. Llamo tiempos netamente institucionales a aquellos en los cuales el noticiero se dedica exclusivamente a mostrarse a sí mismo. Son, en términos generales, los tiempos de presentación, de despedida y, en algunos casos, de transición entre una noticia y otra o entre una noticia y la pausa. Es claro que el noticiero "se está mostrando" permanentemente durante el transcurso del programa, contando para ello con distintas técnicas visuales y sonoras. Los tiempos netamente institucionales son aquellos en que el noticiero no hace más que mostrarse.

14. Para el análisis que sigue, se recurre, ante todo, a las impresiones y sobreimpresiones mostradas en pantalla por el propio noticiero, las cuales operan como síntesis y como guías para la audiovisión de las noticias - de un modo similar a como funcionan los títulos en la prensa gráfica-. Cuando este recurso no es asequible, se considera la presentación oral o escrita del periodista o de la voz en off.

15. Esta categorización recupera-normalizada- la propia clasificación que hacen los telenoticieros. No se distingue entre noticias nacionales e internacionales dado que una primera comparación de ambas -excluidas las noticias sobre Deportes, Espectáculos, Moda y Programación- demostró que, en términos generales, los tres telenoticieros analizados priorizan en ambos planos los mismos temas, siendo que la Criminalidad es el tema más recurrente tanto a nivel nacional $-35 \%$ promedio- como a nivel internacional $-25 \%$ promedio-.

16. Llamo acontecimiento-base a aquel que da origen al "caso" y a su cobertura periodística. Del conjunto de los acontecimientos relatados en una misma noticia, es aquel al cual el propio medio otorga la centralidad del relato. Esa centralidad puede "leerse" en las impresiones y sobreimpresiones en pantalla que, en la mayoría de los casos -y en todos los casos "importantes"-, acompañan a la noticia.

17. Ver Introducción. 
trar categorías actanciales de sujeto y objeto, ni categorías funcionales, que sean comunes a todo relato 18 .

La segunda diferencia, estrechamente vinculada con la anterior, se refiere a la relación que el enunciador establece con su relato. Las noticias sobre criminalidad se caracterizan por un alto grado de univocidad en lo que respecta a dicha relación. Pareciera existir un contrato de lectura previo según el cual el crimen es un tipo de acontecimiento que, salvo rarísimas excepciones, merece ser repudiado, penalizado y prevenido. De ahí que la relación que el enunciador (el noticiero) establece con su relato y que ofrece, a su vez, a su prodestinatario (la audiencia) sea de claro rechazo ${ }^{19}$. En el caso de las noticias políticas y económicas, por el contrario, nos encontramos con la ausencia o la falta de univocidad en lo que respecta a la "valoración" que el enunciador hace de los acontecimientos por él relatados. La misma puede ir desde el silencio hasta la adhesión o el repudio, pero éste nunca es tan contundente como en el caso de las noticias sobre criminalidad.

La combinación de esas dos diferencias nos ofrece dos ámbitos -el de la criminalidad y el de la política- que se distinguen no sólo por sus temas de referencia sino también por su grado de equivocidad.

La política es presentada como un ámbito equívoco, heterogéneo y confuso. Demanda, por tanto, un plus de interpretación de parte del televidente, siendo que el enunciador no le ofrece demasiadas pistas para ello.

La mayor homogeneidad narrativa y la univocidad axiológica propias de las noticias sobre criminalidad ofrecen, por el contrario, la representación de un ámbito con mayor grado de inteligibilidad que el de la política. Toda noticia lleva una suerte de sello que expresa dos verdades indiscutibles: "esto es un crimen y merece ser penalizado”. No caben dudas al respecto. En definitiva, dicha inteligibilidad significa que nos enfrentamos con acontecimientos que se ubican, de modo inequívoco, en los límites de lo social, aquello que la "sociedad" no puede permitir bajo ningún medio 20. Por ello, el enunciador - "nosotros inclusivo" mediante- puede repudiar abiertamente tal tipo de acontecimientos sin atentar contra la pretendida objetividad del género informativo, dado que el carácter indeseable de la criminalidad es considerado, él mismo, "objetivo" 21. El televidente se encuentra, así, frente a un mundo que, claro en su oscuridad, ya viene preinterpretado - por el enunciador y, muy probablemente, por él mismo-y que viene marcado por el valor absoluto de la amenaza tanto contra su propia existencia como contra la sociedad. De todo esto se deriva, a mi juicio, una conclusión que resulta crucial desde el punto de vista pragmático: es mucho más sencillo y efectivo establecer una verdad en el ámbito de la criminalidad que en el de la política.

Una segunda observación nos permite diferenciar a la criminalidad, la política y el deporte en función de su grado de polemicidad y de deseabilidad.

En el caso de la política nos encontramos, ya se dijo, frente a un ámbito equívoco, en el cual la verdad más míni- ma enfrenta serias dificultades para establecerse. Dicha equivocidad parece provenir del carácter polémico y oposicional de la política. Pero proviene también de la decisión mediática de representar ese carácter 22. Polémica entre el oficialismo y la oposición; polémica entre medidas del gobierno y protestas sociales; polémica entre militares y organizaciones de derechos humanos; la política televisada es cada vez menos un ritual público, cada vez más una polémica facciosa 23 . Polémica, por otra parte, frente a la cual el enunciador raramente toma posición 24 .

El caso de las noticias sobre deportes y sobre criminalidad parece ser otro. No porque estén libres de toda polémica sino porque la misma no adquiere el papel casi constitutivo que asume en las noticias políticas.

En el ámbito del deporte, la polémica suele suscitarse en torno a la decisión de un director técnico respecto de la conformación de un plantel; o en torno a la responsabilidad de los organizadores de un determinado certamen; o en torno a la violencia desatada en los estadios. Pero existe un "hecho" básico que es anterior a toda posible polémica: el deporte es, ante todo, una fiesta y, por tanto, un tipo de acontecimiento deseable. El valor festivo del deporte-marcado por el propio enunciador- es resaltado cuando se trata de competencias internaciones: cada triunfo es, en tales casos, una fiesta y un triunfo para todos los argentinos.

En el caso de la criminalidad también se dan polémicas. Las mismas suelen presentarse, principalmente, en torno a ciertos procedimientos policiales y judiciales. Pero hay dos verdades que logran asentarse indiscutiblemente: alguien fue víctima de un crimen y ese crimen es reprobable y punible. El carácter indeseado del crimen y la amplia cobertura del mismo hacen de él una fuente de temor y de amenaza. Una certeza puede establecerse: vivimos en un mundo peli-

18. Considérese que las noticias sobre temas políticos y económicos se refieren a acontecimientos-base tales como el anuncio o implementación de una medida cualquiera de gobierno, la expresión de protestas sociales de los tipos más diversos, las acciones de la oposición política, la evolución de las variables del mercado, la actividad del poder legislativo, los procesos electorales, un laudo internacional, declaraciones políticas de todo tipo, etc.

19. Tomo la categoría de prodestinatario de Verón $\left(1987^{a}\right)$.

20. En este sentido, cabe aclarar que la mencionada inteligibilidad se refiere menos al "origen" o las causas de la criminalidad o a las vicisitudes del esclarecimiento de los casos particulares -todo lo cual suele permanecer, no pocas veces, bajo la más completa oscuridad- que al "sentido" que la Criminalidad reviste desde el punto de vista del "orden social". Es desde ese mismo punto de vista que la política se presenta como un ámbito equívoco.

21. Por ello, puede extenderse al ámbito todo de la criminalidad lo que Best señala a propósito de la victimización de menores: "la victimización de menores cae dentro de la "esfera de consenso de Hallin", donde los periodistas no se sienten compelidos ni a presentar puntos de vista opuestos ni a permanecer como observadores desinteresados" (1990: 99; traducción mía).

22. NUEVEDIARIO, por ejemplo, se autopublicita destacando su decisión de transmitir siempre "las dos caras de la verdad".

23. Esta afirmación supone otra que aquí no puedo más que explicitar: hubo otro tiempo en el cual el ritual público ocupaba, en la televisión argentina, un espacio mayor en los noticieros televisivos.

24. En algunos casos, la relación del enunciador con el relato de las noticias políticas más polémicas puede resumirse bajo la parafrase "esperemos que se resuelva este conflicto". 
groso -criminalmente peligroso- en el cual nadie parece estar a salvo 25 .

Nos encontramos, así, con un mundo que puede caracterizarse a partir de dos oposiciones: la primera, definida a partir del grado de equivocidad del mundo, pone de un lado a la política y del otro a la criminalidad y el deporte; la segunda, definida en función de la deseabilidad del mundo, enfrenta al deporte con la criminalidad y, en parte, con la política. No es que la política sea representada abiertamente como indeseable. Lo que resulta indeseable es su carácter polémico -"esperemos que se resuelva este conflicto"-; y es ese carácter polémico -y faccioso- lo que, en buena medida, arroja a la Política hacia las sombras de la indeseabilidad.

La relación del deporte, la criminalidad y la política con las categorías semánticas 26 arriba presentadas (deseable vs. indeseable, inequívoco vs. equívoco, polémico vs. no polémico) puede ser graficada del siguiente modo:

DIAGRAMA 1

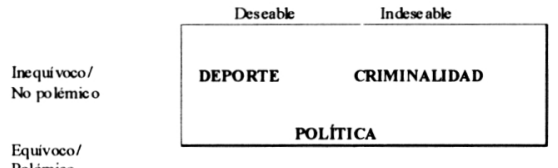

Equivoco/
Polémico

Nota: la ubicación de la politica en las proximidades de la frontera entre lo deseable y lo indeseable indica que su indeseabilidad no es representada tan abierta y tajantemente como en el caso de la criminalidad

Esta distribución nos sugiere una nueva categoría semántica: problemático vs. no problemático. ¿Cuáles de estos grandes temas son, a su vez, grandes problemas sociales? ¿Cuáles no?

El deporte - deseable, inequívoco y no polémico- queda fuera del campo de los problemas sociales. No es que no puedan suscitarse problemas en el deporte. Pero no es común que los mismos sean presentados como problemas sociales. Además, el enunciador del telenoticiero se esfuerza por señalar que esos problemas -cuando surgen- constituyen elementos antideportivos, experiencias contrarias a la "esencia misma del deporte". Si hay problemas, ya no hay fiesta ni deporte.

La criminalidad y la política, por el contrario, operan como lo que Hilgartner \& Bosk (1988) denominan macrocategorías de problemas sociales. Una marcada por su carácter intrínsecamente indeseable; la otra signada por la indeseabilidad de su carácter polémico y por las potenciales $-\mathrm{y}$ no pocas veces temidas- consecuencias de las decisiones y acontecimientos políticos sobre la vida cotidiana; ambas macrocategorías aglutinan, en la narración de los telenoticieros, nuestros principales problemas sociales. No es de extrañar, entonces, que ningún otro acontecimiento reciba tanta cobertura y concentre tanto la atención pública como un atentado terrorista fronteras adentro -el "caso Amia"-. Allí se conjugan los principales problemas y las principales amenazas de nuestra sociedad; aquellos que provienen de la criminalidad y de la política. Ha de ser por eso que, como señala tempranamente Verón (1967), todo acto terrorista parece estar con- denado, en el relato de la cobertura periodística, al sinsentido social.

Si los telenoticieros nos ofrecen, en general, una imagen ambigua y polémica de la actividad política, ello se aprecia especialmente en las noticias sobre el crimen. El relato de los telenoticieros representa de modo contradictorio la participación de las instituciones políticas en el mundo del crimen: por un lado, las instituciones actúan como oponentes, pero, por otro lado, también lo hacen como adyuvantes o, incluso, como victimarios. Es a partir de esa representación contradictoria de las instituciones políticas que los telenoticieros "encuentran" su lugar propio en el mundo del crimen.

\section{LAS INSTITUCIONES POLÍTICAS FRENTE AL CRIMEN}

\section{Las instituciones como oponentes}

En el relato de los tres telenoticieros de nuestro corpus 27 , la policía y el poder judicial aparecen como los principales oponentes del crimen.

La participación de la policía en la lucha contra el crimen es, según el relato de ambos noticieros, la más activa. Siendo que tanto el seguimiento y la investigación de los casos delictivos como la detención de los delincuentes corresponden a la policía, el poder judicial sólo actúa a posteriori o sobre la base del accionar exitoso de aquella. Además, no hay caso en el cual la policía no actúe; ello se ve claramente en su aparición en casi todos los tipos de noticias. Algunas veces como centro -en los operativos por ejemplo-, otras veces con un rol secundario, la policía siempre está presente en el relato.

Los noticieros no sólo relatan la presencia permanente de la policía; la marcan, además, con los valores de necesidad y de obligación. La presencia de la policía es necesaria ya sea para prevenir el delito o para "acabar" con los delincuentes una vez que aquel es cometido. Por eso, la no actuación de la policía es motivo para que se acuse a la misma de negligencia o de incumplimiento de sus tareas. De este modo, los noticieros refuerzan la necesidad de la existencia y del accionar de la policía.

La participación del poder judicial es, en el relato de ambos noticieros, algo menor que la de la policía. Pero no por eso es considerada como menos importante por los

25. Debe tenerse en cuenta, además, que los debates sobre los procedimientos policiales y judiciales remiten la polémica, otra vez, al ámbito de la política: no es sobre el carácter criminal del hecho que se debate sino sobre el papel de las instituciones políticas en el "mundo del delito". Este punto será analizado en la próxima sección.

26. Ver Greimas (1987).

27. El relato de los tres telenoticieros sobre la política en general y, especialmente, sobre el problema de la criminalidad y la actitud de las instituciones políticas frente al mismo es altamente homogéneo. De ahí que, prácticamente, no se establezcan diferencias entre el modo en que uno y otro noticiero construyen la participación de las instituciones políticas en el mundo del crimen. 
telenoticieros. La participación del poder judicial también está marcada por los valores de necesidad y de obligación. Esto se aprecia con gran claridad en el relato de los reclamos de justicia realizados por la víctimas o -más frecuentemente- por sus deudos. Los noticieros no sólo relatan esos reclamos con la mayor seriedad, en algunos casos los acompañan con sus propios reclamos de justicia. Veamos un ejemplo. Ante un resonante caso -el caso María Soledad-, en el cual el poder judicial no logra esclarecer el crimen cometido, la conductora de TELENOCHE cierra la noticia con un largo comentario: “¿Cómo puede ser? Todos los recursos. Toda la información. Todo lo que se puede tener de técnico como para resolver, como para saber. ¿Quién para esto? ¿Por qué paran esto? ¿Quién está detrás de esto? Porque hay gente detrás de esto. Esto no es casualidad. ¿Cómo puede ser que no se pueda averiguar, que siga la impunidad? ¿Cómo vamos a hacer para que la gente vuelva a creer en nuestra justicia? -con el dedo índice hacia la cámara-Así no”. Debajo de la crítica a la incompetencia casi deliberada -rasgo que, como efecto de demostración, puede expandirse desde un caso particular hasta el funcionamiento mismo del poder judicialestá presente el presupuesto según el cual el poder judicial es imprescindible.

La importancia otorgada al funcionamiento del poder judicial tiene como contracara la necesidad de garantizar la seguridad de la vida cotidiana. Al respecto, TELEFE produce en una oportunidad un Informe sobre seguridad que es muy revelador. En un momento determinado del informe, dice la conductora: "no hablamos de justicia por manos propias, hablamos de inseguridad. Ante un estado impotente para resolver este fenómeno, la gente opta por protegerse a través de diferentes caminos. El $20 \%$ de los bonaerenses tiene armas en sus casas, la mayoría de ellas no habilitadas. Esto pasa cuando la seguridad queda condenada a la autodefensa porque el estado resulta impotente ante ese creciente fenómeno". La centralidad del estado en la defensa de la seguridad cotidiana es reforzada mediante el otorgamiento de la palabra a una voz especializada, la de un criminólogo reconocido: "los que piensan en la venganza privada están deslegitimando a la justicia y, por lo tanto, también a la democracia; la gente en la democracia debe exigir la seguridad porque los señores que nos gobiernan son nuestros representantes. En cuanto a las formas de autodefensa, es preferible el gas paralizante a un arma, porque quien tiene un arma tiene a veces alguna suerte de ideas, de fantasías o de sueños de heroísmo moral". La palabra especializada del criminólogo advierte que la especificidad del estado como garante de la seguridad reside en la provisión de justicia, porque la justicia es la vía democrática para garantizar la seguridad. Por eso, ninguna apelación a la justicia por manos propias, al "heroísmo moral" es aconsejable.

Ese rechazo del "heróismo moral" a favor del papel de la justicia estatal puede apreciarse en el relato sobre los casos de justicia por manos propias. En una noticia de TELEFE sobre un caso muy resonante, por ejemplo, la abogada de los familiares de la víctima señala: "el fallo resalta que el monopolio de la justicia está en manos del estado y no de particulares". Como cierre de nota, el reportero refuerza la opinión casi weberiana de la abogada diciendo: "debemos luchar por una sociedad donde estén presos los ladrones de pasacassettes pero también aquellos que entienden que hacen justicia obrando por mano propia”. Para TELEFE, la cuestión parece clara: sólo la "justicia de los fueros" puede y debe garantizar la seguridad. De ahí que cuanto peor el funcionamiento del poder judicial, mayores y más graves serán las medidas de autodefensa.

Junto con la policía aparecen como oponentes otras fuerzas de seguridad; a saber: la gendarmería nacional, la prefectura naval argentina e, incluso, empleados de seguridad privados. Esos oponentes cumplen exactamente las mismas funciones que la policía, sólo que su participación es mucho menor que la de esta última.

Al margen de las fuerzas de seguridad y del poder judicial, se presentan como oponentes otras instituciones políticas. Se trata del gobierno nacional y de los gobiernos provinciales -en especial, el de la provincia de Buenos Aires-. La aparición de estos oponentes es muy esporádica y su participación poco activa. Su actuación no pasa de la formulación de declaraciones o del anuncio o la promesa de medidas a tomar.

Fuera de las instituciones políticas, los medios informativos -especialmente los propios noticieros- cumplen un papel muy especial como oponentes. En primer lugar, porque su cobertura periodística es una forma de dar publicidad a los acontecimientos delictivos y de poner a la población en estado de alerta sobre las eventualidades delictivas de la "sociedad indefensa", como dice uno de los comentaristas de TELEFE. Pero no sólo por eso. En ciertas ocasiones, los noticieros, por ejemplo, reclaman por su propia cuenta -y en pretendida consonancia con "la gente" - el esclarecimiento judicial de casos aún irresueltos. En ciertos casos van más lejos todavía y denuncian ellos mismos algunos delitos -por lo general, ilícitos administrativos- o colaboran con la policía y el poder judicial en la lucha contra el crimen.

\section{Las instituciones como victimarios}

Tres son las instituciones que aparecen como victimarios en el relato de los noticieros: la policía, las fuerzas armadas -FFAA- y el poder político en general. Estas instituciones-victimarios están asociadas a la "violencia institucional" en los dos primeros casos y a la criminalidad administrativa o "corrupción" en el tercero.

La policía es acusada de los más variados crímenes, pero el que mayor atención concentra en ambos noticieros es el homicidio, crimen para el cual los noticieros han introducido una denominación especial cuando el victimario es un miembro de la policía: "el gatillo fácil”.

El relato sobre el tratamiento judicial de estos casos es ambiguo, lo cual se expresa en la formulación de dos variaciones distintas en el mismo relato. Por un lado, poder judicial aparece como un claro oponente, investi- 
gando, procesando, enjuiciando y dictando fallos condenatorios. Por otro lado, es retratado como un adyuvante, reprochado por la no resolución de los casos, por la levedad de los fallos dictados o por el desprocesamiento infundado de los imputados. No es posible discriminar los casos concretos según cada una de estas variaciones, dado que las mismas suelen presentarse conjuntamente en el relato de un mismo caso. Tampoco parece posible adscribir dichas versiones a enunciadores bien diferenciados, puesto que un mismo enunciador puede dar lugar tanto a una como a otra versión. Por eso, deben ser consideradas como versiones de un mismo -y por demás complejo- tipo de relato.

En cuanto a las FFAA, siendo menores los casos relatados, se destacan dos crímenes: el Asesinato y el Secuestro. En este caso, el tratamiento judicial parece inequívoco: el poder judicial aparece sólo como oponente al crimen. Por su parte, ninguna otra institución suele adyuvar con el crimen militar, salvos las propias FFAA, las cuales son sospechadas de encubrimiento.

El poder político, por su parte, es acusado de una serie de crímenes administrativos resumibles bajo el cargo de corrupción. Esta acusación que toca a varios funcionarios y dirigentes políticos se extiende como sospecha al conjunto del poder político. En cuanto al tratamiento judicial, debe señalarse que, si bien no aparece como adyuvante, en ningún caso la intervención judicial logra esclarecer definitivamente la acusación que pesa sobre el poder político. Este hecho -ocasionalmente remarcado por los noticieros-ayuda a alimentar aún más la sospecha volcada sobre el poder político.

\section{Las instituciones como adyuvantes}

En ciertas ocasiones, el relato de los noticieros reprocha a la policía no actuar conforme a su deber, ocasiones en las cuales la policía no actúa como oponente sino como adyuvante del crimen. Se recrimina a la policía por negligencia, por no recepción de denuncia, por allanamiento de la vivienda de una víctima, por no prevención del delito o por hostigamiento. De este modo, la modalidad según la cual la policía actúa de modo contrario a su función es doble: como victimario y como adyuvante.

Sin embargo, el principal adyuvante entre las instituciones parece ser el poder judicial. Los telenoticieros, al menos, prestan mayor atención a los casos en que el poder judicial actúa como adyuvante del crimen. A tal punto que nos ofrecen una serie de noticias donde el relato predominante se refiere exclusivamente a casos en los cuales el poder judicial no ha llegado a resolución alguna o respecto de los cuales ha dictado una sentencia que los noticieros -en consonancia con los deudos de las víctimas- consideran demasiado leve. Este reproche de los telenoticieros al poder judicial es muy serio dado que se trata de casos que han logrado gran resonancia pública. Igualmente preocupante es ese reproche cuando se trata de la "violencia policial": aquí el poder judicial no sólo es recriminado por el no escla- recimiento de los casos, sino que es sospechado de hacerlo deliberadamente y de estar en connivencia con la policía. Otras funciones adscriptas al poder judicial -como adyuvante- son la no investigación, la lentitud procesal y el dictamen de sanciones excesivas.

La caracterización del poder judicial como adyuvante alcanza al propio código penal, el cual es criticado por falencias en la penalización del robo de bebés o por el dictamen de condenas livianas para ciertos tipos de crímenes.

Existen dos tipos de noticias en los cuales, si bien no aparece abiertamente como adyuvante, el poder judicial no realiza un papel muy decoroso: las noticias sobre corrupción y las noticias sobre "violencia política". En ambos casos, el relato de los noticieros nos muestra un poder judicial que actúa, que trabaja, que investiga, pero que nunca llega a una resolución concreta. Si bien no encontramos en el plano manifiesto del relato de los telenoticieros un tono de reproche, la reiteración de casos en los cuales el poder judicial nunca llega a esclarecer el crimen cometido -casos que, por otra parte, son de suma gravedad política dado el tipo de delito en cuestión-, más alguna alusión ocasional por parte de los conductores, comentaristas y reporteros del telenoticiero, representa al poder judicial bajo un papel próximo al del adyuvante.

El máximo poder político -gobierno nacional, parlamento, gobierno de la provincia de Buenos Aires- constituye, según el relato de los telenoticieros, otro oponente de peso. Los principales reproches dirigidos a ese poder son los siguientes: no legislar satisfactoriamente, no implementar medidas de seguridad adecuadas e, incluso, obstruir el esclarecimiento de crímenes en los cuales están implicados dirigentes oficialistas.

Aparte de las ya mencionadas, existen otras dos instituciones que son representadas por los telenoticieros como adyuvantes: las FFAA, acusadas de encubrir a los verdaderos autores de un crimen cometido en dependencias militares y el sistema penitenciario, acusado de otorgar tratamiento preferencial a policías detenidos.

En el caso de TELEFE, también es recriminada la Sociedad en su conjunto: uno de los columnistas -el que comenta los "casos policiales"- advierte que son la perversión y la indefensión generalizadas de la sociedad las que estimulan crímenes tales como el tráfico y consumo de drogas o que incitan, cual "mala consejera", a hacer justicia por mano propia.

\section{El cuadro general}

Para recapitular el análisis precedente, a continuación presento, mediante el Diagrama 2, el cuadro general de los papeles que las instituciones cumplen en el mundo del delito y las funciones bajo las cuales desempeñan cada uno de esos papeles. En la sección siguiente avanzaremos en el análisis de ese cuadro general y nos centraremos en el papel que los telenoticieros se otorgan a sí mismos respecto del mundo del crimen. 


\begin{tabular}{|c|c|c|c|c|c|}
\hline \multirow{2}{*}{\multicolumn{3}{|c|}{$\begin{array}{l}\text { LASINSTITUCIONES COMBATEN EL CRIMEN } \\
\text { Las instituk iones como oponentles }\end{array}$}} & \multirow{2}{*}{\multicolumn{3}{|c|}{ LAS INSTITUCIONES NO COMBATEN EL CRIMEN }} \\
\hline & & & & & \\
\hline 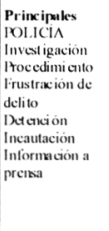 & 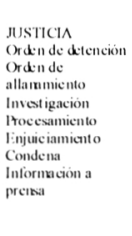 & $\begin{array}{l}\text { MEIDIOS IN- } \\
\text { lORM ATIVOS } \\
\text { Intormancion } \\
\text { Denumcia } \\
\text { Colaboración con } \\
\text { policia y yusticia } \\
\text { Reclamo de } \\
\text { cestarecimicinto) }\end{array}$ & 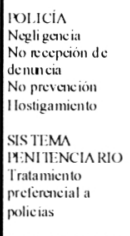 & 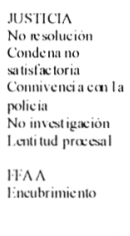 & 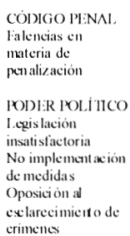 \\
\hline 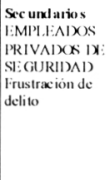 & 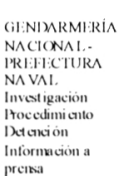 & 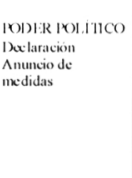 & 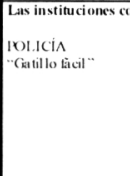 & 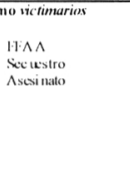 & 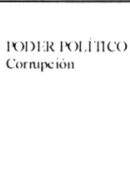 \\
\hline
\end{tabular}

\section{EL LUGAR DE LOS TELENOTICIEROS EN EL MUNDO DEL CRIMEN}

\section{Los telenoticieros como "representantes de la gente"}

Como vimos en la sección anterior, el relato de los telenoticieros nos ofrece una imagen bifronte sobre el desempeño de las instituciones en el mundo del crimen. De un lado, las instituciones se oponen al crimen y al hacerlo cumplen con su función y su deber, lo cual -especialmente en los casos de la policía y del poder judicial- resulta imprescindible. Pero las instituciones muestran también su otra cara: la de su participación y connivencia con el crimen. Ya sea como adyuvantes o como victimarios, las instituciones suelen desatender sus funciones e, incluso, ir contra ellas. Consideremos a continuación la policía, el poder judicial, las FFAA y el poder político.

La policía, a la vez que aparece -junto con el poder judicial- como el principal oponente, es retratada también como un fiero victimario. Fiero porque no hay crimen más temible que el cometido por quienes deben combatir el crimen. Fiero, además, porque el tratamiento judicial de la "violencia policial" socava la confiabilidad en el poder judicial en tanto pone en duda, más que cualquier otro caso, el necesario carácter imparcial del poder judicial.

En el caso del poder judicial, el relato de los telenoticieros contrapone sus funciones de oponente con su desempeño como adyuvante. Es necesario que el poder judicial actúe porque la justicia es la única garantía contra la inseguridad. Y muchas veces lo hace, y sabe hacerlo bien. Pero, en varias oportunidades, el poder judicial actúa en sentido contrario, impidiendo -por incompetencia, por negligencia o por connivencia- que el crimen se esclarezca. Impidiendo, como lo señalan los reclamos de los deudos de las víctimas y de los propios noticieros, "que se haga justicia".

Junto con la policía y el poder judicial, aparecen dos oponentes institucionales de peso: las FFAA y el poder político. En el primer caso, su mera actuación como victimario refuerza el desprestigio en que han caído las FFAA durante las últimas décadas, las cuales han dejado de ser una "garantía de orden y seguridad". En el segundo caso, la actuación como adyuvante e, incluso, como posible victimario refuerza la falta de representatividad del poder político: los dirigentes hacen exactamente lo que Ud. no quiere que hagan, lo que Ud. no haría si estuviera en el lugar de ellos.

¿Cómo entender este cuadro bifronte que los telenoticieros pintan sobre las instituciones? ¿Presupone el desprestigio del orden institucional? Si y no.

¿Por qué si? Porque, evidentemente, muestra el mal desempeño de las instituciones que se supone están para garantizar nuestra seguridad y, en un plano más amplio, nuestro bienestar.

¿Por qué no? Porque, sin embargo, los telenoticieros no reclaman ni ofrecen un orden alternativo. $\mathrm{O}$ mejor dicho, el orden alternativo que reclaman es el del "correcto" funcionamiento de las instituciones.

El reclamo de los telenoticieros por el correcto funcionamiento de las instituciones, al igual que el reclamo de las Marchas del Silencio, evoca aquellos movimientos sociales cuyo objetivo principal es, según Mellucci (1994), restablecer el funcionamiento de una institución poco funcional. De ese modo, los reclamos contra la policía, contra el poder judicial, contra el poder político no pretenden la desactivación de los mismos sino todo lo contrario: su correcto desempeño. ¿Cuál es ese correcto desempeño? En este punto, los telenoticieros son imprecisos a la vez que "demagógicos". Recordemos el comentario de la conductora de TELENOCHE cuando se pregunta: "cómo vamos a hacer para que la gente vuelva a creer en nuestra justicia". Su respuesta no es afirmativa sino que opera por descarte: "así no" es el remate del comentario. La única respuesta afirmativa apela, en realidad, a respetar el fundamento de la representatividad de las instituciones: "lo que la gente quiere". "Lo correcto no es sólo lo que es bueno para la gente, sino lo que gente quiere, porque la gente sabe lo que es bueno para ella", parecerían decir los periodistas. Por este camino, los telenoticieros reivindican el carácter representativo de las instituciones. "Porque estos señores son nuestros representantes - decía el criminólogo entrevistado por TELEFE-, debemos exigirles seguridad y justicia". He ahí la clave del papel que los telenoticieros pretenden para ellos mismos: el papel de nexo entre la gente y ese poder político lejano y corrupto, esas instituciones necesarias pero proclives al mal desempeño. Los telenoticieros descubren que las instituciones de la democracia no son lo suficientemente representativas a la que intentan suplir ellos mismos esa falta, no tanto en lo que refiere a las cuestiones de la "agenda política" como respecto de aquellas otras que, por su tratamiento periodístico, parecen ser primarias -la justicia, la seguridad-y respecto de las cuales las instituciones deben cumplir funciones insoslayables. De este modo, lo que desde un punto de vista formal-sintagmático puede aparecer como una contradicción (un mismo actor cumpliendo roles contra-

28. Presento a los oponentes, adyuvantes y victimarios en mayúsculas y a sus respectivas funciones en minúsculas y normalizadas en la forma sustantiva. Distingo entre oponentes primarios y secundarios replicando la jerarquía otorgada por los telenoticieros. 
rios) encuentra su solución en el rol que los telenoticieros pretenden para ellos mismos: no sólo como mediadores entre la gente y las instituciones sino también como guardianes de estas últimas. Es posible que las instituciones funcionen correctamente; sólo hace falta pisarles los talones cuando es necesario. Porque son imperfectas, las instituciones son perfectibles y pueden ser mejoradas. Para colaborar en esa tarea están los telenoticieros, quienes no hacen nada sino en nombre y representación de la gente. Podemos graficar ese papel que los telenoticieros se arrogan como "representantes de la gente" mediante las categorías actanciales de Greimas: como nos muestra el Diagrama 3, los telenoticieros (sujeto 2) se presentan como agentes que, en representación de la gente (destinador), luchan en favor de la justicia y la seguridad (función), no sólo informando sobre los casos criminales, sino también presionando y controlando a las instituciones políticas (sujeto 1) para que cumplan con su papel como representantes "naturales" de la gente y luchen "como les corresponde" en favor de la justicia y la seguridad. La gente, por su parte, no es solamente el destinador del poder y la autoridad de las instituciones políticas y de los telenoticieros: es también el destinatario de sus acciones, en tanto es para beneficio de la gente que unas y otros deben garantizar la justicia y la seguridad. Se cierra, de este modo, el círculo virtuoso de la representación.

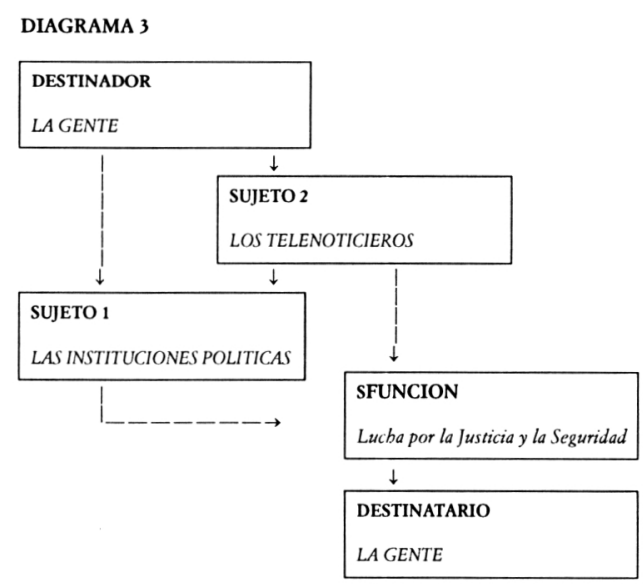

\section{Los límites del orden}

Es evidente que la capacidad de los telenoticieros para presentarse como representantes de la gente depende de su referencia a la constitución del orden. La intervención de los telenoticieros en las cuestiones de justicia y seguridad y su presión sobre las instituciones políticas se "justifican" como medidas tendentes a resguardar o a procurar un determinado orden social. Como ya vimos, el orden que los telenoticieros de nuestro corpus tratan de fortalecer o de garantizar es el del correcto funcionamiento de las instituciones. Ahora bien, al presentarse como guardianes del orden, los telenoticieros "muestran" permanentemente las fallas de las instituciones, los puntos en los cuales el orden no cierra y sobre los cuales es necesario actuar. Muestran, de esa manera, la fragilidad de su propia tarea: poco feliz es su papel como guardianes si periódicamente se renueva la información sobre el mal desempeño de las instituciones. Sin embargo, porque la tarea nunca acaba, los telenoticieros pueden y "deben" representar, día tras día, su agónico papel. De algún modo, la rutina diaria de los telenoticieros se justifica porque su tarea es necesaria a la vez que inacabada. Por eso, más que un cierre del orden, la autorrepresentación de los telenoticieros como guardianes y mediadores expresa la búsqueda de un orden deseado así como la imposibilidad del mismo. Con todo, aún cuando "muestren" diariamente que el orden deseado no es posible, los telenoticieros necesitan afirmar la posibilidad de ese orden para dar sustento a su acción. Es aquí donde reside, siguiendo a Laclau, "lo ideológico" del relato de los telenoticieros. "Lo ideológico no consistiría en la falsa representación de una esencia positiva, sino exactamente en lo contrario: consistiría en el no reconocimiento del carácter precario de toda positividad, en la imposibilidad de toda sutura final. Lo ideológico consistiría en aquellas formas discursivas a través de las cuales la sociedad trata de instituirse a sí misma sobre la base del cierre, de la fijación del sentido, del no reconocimiento del juego infinito de las diferencias. Lo ideológico sería la voluntad de "totalidad" de todo discurso totalizante. $\mathrm{Y}$ en la medida en que lo social es imposible sin una cierta fijación del sentido, sin el discurso del cierre, lo ideológico debe ser visto como constitutivo de los social. Lo social sólo existe como el vano intento de instituir ese objeto imposible: la sociedad. La utopía es la esencia de toda comunicación y de toda práctica social" (Laclau, 1993: 106) 29. En este sentido, el relato de los telenoticieros nos ofrece lo que Zizek llama una fantasía social o ideológica: "la noción de fantasía social es... una contrapartida necesaria del concepto de antagonismo: fantasía es precisamente el modo en que se disimula la figura antagónica. Dicho de otra manera, fantasia es el medio que tiene la ideología de tener en cuenta de antemano su propia falla. La tesis de Laclau y Mouffe de que "la Sociedad no existe", de que lo Social siempre es un terreno incongruente estructurado en torno a una imposibilidad constitutiva, atravesado por un "antagonismo central" -esta tesis implica que todo proceso de identificación que nos confiere una identidad socio-simbólica fija está en definitiva abocado al fracaso. La función de la fantasía ideológica es disimular esa incongruencia, el hecho de que "la Sociedad no existe", y compensarnos así por la identificación fallida" (1992: 174-175; énfasis originales). En efecto, para "justificar" su papel y su tarea, los telenoticieros hacen referencia a un orden deseado -el del correcto funcionamiento de las institucionesque consideran no vigente o no plenamente vigente pero que postulan como posible. Ese orden deseado anula, como posibilidad y como "necesidad", el antagonismo existente entre las instituciones y la gente, el cual se expresa en el

29. Cabe aclarar que no estamos hablando de un "problema" específico de los telenoticieros o de los medios de comunicación, al cupiera contraponer una perspectiva científica. Lo ideológico debe ser visto como constitutivo de lo social dado que la búsqueda de lo imposible -en nuestro caso, la plenitud del orden- pertenece a la "ontología de lo social" (Laclau, 1993; 1996). 
papel de las primeras como victimario y adyuvante del crimen. Bajo el orden deseado, las instituciones "recuperan" plenamente su "legítimo" rol como representantes del pueblo, esto es, reafirman su papel como oponentes del crimen. Debe advertirse que ese orden deseado no supone la eliminación de todo antagonismo. Como sostiene Laclau (1996), la definición de un orden depende de la posibilidad de establecer sus límites, lo cual depende, a su vez, de la posibilidad de postular una exterioridad radical que, ubicada "más allá" del orden, amenace al mismo de modo absoluto. Es claro que, en el relato de los telenoticieros -como en tantos otros-, el papel de la exterioridad radical es otorgado a la criminalidad. No es ese el antagonismo que la fantasía ideológica del relato de los telenoticieros se propone "disimular", sino el que proviene de quienes, se supone, deben estar en relación de equivalencia con la gente, de quienes deben ser los guardianes de las relaciones equivalentes de los buenos ciudadanos. He ahí el punto de mayor tensión del relato: cuando nos presentan a los victimarios y adyuvantes del crimen, los telenoticieros nos ofrecen una imagen antagónica de quienes deberían ser sus oponentes. ¿Cómo disimular ese antagonismo? Es allí cuando se recurre a la fantasía ideológica del correcto funcionamiento de las instituciones, la cual, de paso, permite fortalecer la imagen de los telenoticieros como representantes de la gente. Por esa vía, queda claro cuáles son los verdaderos enemigos: los criminales a secas, sin importar que mañana la policía vuelva a matar, que los jueces jamás logren resolver nada.

Tenemos entonces que, para disimular, anular, mitigar el carácter bifronte de las instituciones, el relato de los telenoticieros nos ofrece la fantasía del correcto funcionamiento del orden institucional. Sin embargo, esta fantasía es ella misma bifronte, en tanto ella misma muestra, como su reverso, su carácter ideológico. ¿Por qué? Porque toda fantasía lleva consigo el síntoma de la imposibilidad de lo social, el síntoma del inmanente antagonismo social, en definitiva, el síntoma de la fantasía misma. Como afirma Zizek, "atravesar" la fantasía social es asimismo correlativo a la identificación del síntoma” (1992: 175; énfasis original). Así como el judío -compendio de todos los males humanosconstituye el síntoma que manifiesta la imposibilidad de la fantasía corporativista aria 30 , lo mismo sucede con la criminalidad en la fantasía del correcto funcionamiento institucional; si la criminalidad persiste, y si las instituciones no pueden dejar de recurrir a ella, es porque, en definitiva, el correcto funcionamiento de las instituciones es sólo eso: una fantasía. Depositar en la criminalidad todos los males imaginables nos permite seguir viviendo pero no nos exorciza: nada libra a lo social de su constitutivo carácter antagónico, el cual, por su parte, hace de "lo ideológico" un elemento constitutivo de lo social.

Pero, si toda fantasía va acompañada del síntoma que manifiesta su carácter de mera fantasía, ¿no equivale ello a decir que toda fantasía implica el reconocimiento de la imposibilidad de lo social y que, por tanto, no es correcto tildarla de ideológica (al menos, si entendemos lo ideológico como el no reconocimiento de la imposibilidad de lo social)? Una primera respuesta afirmativa nos llevaría a aceptar la teoría del cinismo de Peter Sloterdijk (1989), según la cual la ideología es, en realidad, cínica. El cinismo supone que quien actúa está al tanto de la distancia existente entre la máscara de la fantasía ideológica y la "realidad" social, pero, pese a ello, insiste en la máscara. Sloterdijk rectifica una célebre frase de Marx en los siguientes términos: los hombres saben muy lo que hacen y, sin embargo, lo hacen. En principio, esta actitud cínica anula la fantasía ideológica tal como aquí la presentamos, puesto que reconoce absolutamente la imposibilidad de la fantasía. Zizek, sin embargo, nos advierte que la fantasía ideológica no es, como en Sloterdijk, una cuestión cognoscitiva sino práctica. Mientras el cinismo consiste en actuar la máscara aún conociendo su carácter de máscara, la fantasía ideológica se apoya en una creencia práctica que bien puede contradecir nuestro "conocimiento teórico": "la creencia, lejos de ser un estado "íntimo", puramente mental, se materializa siempre en nuestra actividad social efectiva: la creencia sostiene la fantasía que regula la realidad social" (Zizek 1992:64; énfasis originales). Zizek ejemplifica el papel de la creencia mediante el caso de la burocracia: "todos sabemos que la burocracia no es todopoderosa, pero nuestra conducta "efectiva" en presencia de la maquinaria burocrática está ya regulada por una creencia en su omnipotencia" (1992:65; énfasis original). No importa, entonces, si el no reconocimiento que define "lo ideológico" se da o no en el plano del conocimiento. Es el nivel de la acción el que importa: es al hacer que se ignora el carácter ilusorio de la fantasía. "Lo ideológico" consiste, entonces, en actuar como si la fantasía no fuese tal y en la necesidad de actuar de ese modo. Si los telenoticieros no pudieran afirmar su creencia en la fantasía del correcto funcionamiento de las instituciones, toda su actividad informativa carecería de sentido, dado que no tendrían un parámetro para determinar la "gravedad" de los acontecimientos relatados y, en consecuencia, la importancia de cubrir los mismos.

\section{¿En sintonía?}

Volvamos, para terminar, al papel de los telenoticieros como representantes de la gente. Si bien es cierto que -como se ha destacado varias veces en el ámbito de la teoría política- toda representación es constituyente de lo representado, no debe descartarse que exista alguna "sintonía" entre el relato de los telenoticieros sobre la criminalidad y las percepciones que sus audiencias tienen sobre ese mismo problema. Si bien excede los alcances de este trabajo determinar las características de esa "sintonía", para lo cual haría falta desarrollar un estudio de recepción, cabe afirmar, cuando menos, que los telenoticieros están interesados en responder a las expectativas -manifiestas o latentes- de la mayor cantidad de personas posible. Creo que no sería aventurado confirmar que la amplia cobertura que los

30. "Hemos de reconocer en las propiedades atribuidas al "judío" el producto necesario de nuestro sistema social; hemos de reconocer en los "excesos" que se atribuyen a los "judíos" la verdad sobre nosotros mismos (Zizek, 1992: 175; énfasis originales). 
telenoticieros otorgan a los casos de criminalidad y la imagen de las instituciones que nos ofrecen mediante el relato de los mismos dependen, en gran medida, de una fantasía ideológica que los telenoticieros y la gente comparten por igual: la fantasía de un orden justo y seguro, cuyos límites sean claros y donde las instituciones y los criminales se encuentren nítidamente ubicados a ambos márgenes de dichos límites. De ahí el impacto que pueden producir aquellos casos que, como el de María Soledad, combinan criminalidad y política. Mientras que, por un lado, muestran el lado más indeseable de la política y la versión más amenazante de la criminalidad, por el otro, refuerzan la necesidad de las instituciones políticas para la satisfacción de bienes tan primarios como la justicia y la seguridad. En un mismo acto, los "reclamadores" de justicia y seguridad expresan su desconfianza y su repudio respecto de las instituciones que ejercen el control estatal de la violencia a la vez que piden "más estado".

Las conclusiones de este trabajo pueden despertar dudas y objeciones sobre el papel de los medios. ¿Pueden ser éstos tomados como "legítimos" representantes de la gente o se trata, sin más, de cínicos mercaderes de problemas sociales? Los apocalípticos nos advertirían que, para los productores de noticias, los temas y problemas sociales no son realmente un objeto de reclamo sino, como afirman Hilgartner \& Bosk (1988), una buena oportunidad para hacer negocios o, simplemente, otro día de trabajo. Resaltarían, además, que casos como el de María Soledad reúnen una dosis inmejorable de espectacularidad y sensacionalismo, requisitos indispensables para mantener o mejorar el rating (y las ganancias) de los telenoticieros. Los integrados, por su parte, retrucarían que no importan tanto las motivaciones de quienes producen las noticias como los efectos que éstas pueden generar; ellos resaltarían el papel positivo de los medios en la instalación pública de temas tales como la justicia y la seguridad. Por mi parte, considero que la atención debería ser llevada desde las motivaciones y los efectos de las producciones mediáticas hacia nuestros "poderes" 31: ¿qué es lo que nosotros, vulgares ciudadanos, podemos hacer con los medios de comunicación masiva? ¿cómo podemos servirnos de ellos? Me aventuro a afirmar que esa misma pregunta se la hacen quienes se plantean, por ejemplo, si organizar o no una Marcha del Silencio para expresar sus reclamos.

\section{BIBLIOGRAFÍA}

BEST, Joel (1989): "Extending the constructionist perspective: a conclusion-and an introduction", en Joel BEST (ed): Images of Issues, New York: Aldine.

Best, Joel (1990): Threatened Children: Rhetoric and Concern about Child Victims, Chicago: University Chicago Press.

DADER, José Luis (1990): "La canalización o fijación de la "agenda" por los medios". En Alejandro MuÑOZ-AlONSO et altri: Opinión pública y comunicación política. Madrid: Eudema.

De Fleur, Melvin \& Sandra BALL-ROKEACH (1991): Teorías de la comunicación de masas. México: Paidós.

ECO, Umberto (1981): Lector in fabula . La cooperación interpretativa en el texto narrativo. Barcelona: Lumen.
EDELMAN, Murray (1991): La construcción del espectáculo político. Buenos Aires: Manantial.

FRIGERIO, Alejandro (1995): La construcción de los problemas sociales: cultura, política y movilización, mimeo.

GoOdE, Erich \& Nachman BEN-YEHUdA (1994): "Moral Panics: Culture, Politics, and Social Construction”. En Annual Review of Sociology, 20.

Greimas, Algirdas Julien (1987): Semántica estructural. Investigación metodológica. Madrid: Gredos.

GREIMAS, Erich \& Nachman BEN-YEHUDA (1993): La semiótica del texto: ejercicios prácticos. Análisis de un cuento de Maupassant. Barcelona: Paidós.

HiLgarTnER, Stephen \& Charles Bosk (1988): "The Rise and Fall of Social Problems: A Public Arenas Model". En American Journal of Sociology, 94.

IMBERT, Gérard (1990): "Por una socio-semiótica de los discursos sociales (acercamiento figurativo al discurso político)". En Manuel GARCía FERRANDO et altri (comps): El análisis de la realidad social. Métodos y técnicas de investigación. Madrid: Alianza.

LACLAU, Ernesto (1993): Nuevas reflexiones sobre la revolución en nuestro tiempo. Buenos Aires: Nueva Visión.

LAClAU, Ernesto (1996): Emancipación y diferencia. Buenos Aires: Ariel.

MelluCCI, Alberto (1994): “¿Qué hay de nuevo en los "nuevos movimientos sociales”?”. En E. LARAÑa \& J. GUSFIELD (comp): Los nuevos movimientos sociales. De la ideología a la identidad. Madrid: Centro de Investigaciones Sociológicas.

Ricoeur, Paul (1985): Hermenéutica y acción. Buenos Aires: Docencia.

Ricoeur, Paul (1996): Sí mismo como otro. México: Siglo Veintiuno Editores.

Rodrigo Alsina, Miguel (1989): La construcción de la noticia. Barcelona: Paidós.

SCHnEIDER, Joseph (1985): "Social Problems Theory: The Constructionist View". En Annual Review of Sociology, 11.

SCHNEIDER, Joseph (1993):"Members Only": Reading the Constructionist Text". En J. Holstein \& G. Miller (eds): Reconsidering Social Constructionism: Debates in Social Problems Theory. New York: Aldine.

SLOTERDIJK, Peter (1989): Crítica de la razón cínica. Tomos I y II. Madrid: Taurus.

VERÓN, Eliseo (1967): Ideología y comunicación de masas: la semantización de la violencia política. Buenos Aires: Centro de Investigaciones Sociales del Instituto Torcuato Di Tella.

VERÓN, Eliseo (1983a ): Construir el acontecimiento. Los medios de comunicación masiva y el accidente de la central nuclear de Three Mile Island. Barcelona: Gedisa.

VERÓN, Eliseo (1983b): "Il est la, je le vois, il me parle". En Communications, 38. París, traducción de cátedra.

VERÓN, Eliseo (1986): La mediatización. Buenos Aires: Facultad de Filosofía y Letras.

VERÓN, Eliseo (1987a ): "La palabra adversativa. Observaciones sobre la enunciación política”, en Eliseo VERÓN (comp): El discurso político. Lenguajes y acontecimientos. Buenos Aires: Hachette.

VERÓN, Eliseo (1987b): La semiosis social. Fragmentos de una teoría de la discursividad. Barcelona: Gedisa.

ZIZEK, Slavoj (1992): El sublime objeto de la ideología. México: Siglo XXI.

31. En el sentido que Ricoeur $(1985,1996)$ da a este término. 